\title{
Did We Learn Evidence-Based Medicine in Medical School? Some Common Medical Mythology
}

\section{Douglas S. Paauw, MD}

Despite advances in medicine occurring on a daily basis, physicians are slow to change their practices. Many different interventions have been studied, including continuing medical education (CME) courses, computerized reminder systems, printed monographs, and CME home reading materials. ${ }^{1,2}$ The most common forms of updating information-CME courses and home reading materials - have little impact on changing professional practices. ${ }^{1,2}$ Physicians rely on a core knowledge base acquired in medical school and through subsequent experiential learning. Much of what is practiced and taught in medicine is based on plausible theory, but in some cases there is no direct evidence to support it. Some practices are grandfathered in with no questioning as to the validity of what is taught or practiced.

The purpose of this article is to look at several different medical myths and explore what is available in the literature to counter or offer alternatives to long-held beliefs.

\section{Methods}

MEDLINE was searched for relevant English language articles published between January 1976 and July 1998 using the following terms or combination of terms: "myths," "oral vitamin $\mathrm{B}_{12}$ replacement," "eye patch and corneal abrasion," "adverse effects of beta-blockers," "beta-blockers and hypoglycemia," "beta-blockers and depression," "insulin sliding scale," and "narcotics and abdominal pain." Relevant articles and bibliographies were reviewed to find articles published be-

Submitted, revised, 10 Oct 1998.

From the Division of General Internal Medicine, University of Washington School of Medicine, Seattle. Address reprint requests to Douglas $\mathrm{S}$. Paauw, $M D$, Division of General Internal Medicine, School of Medicine, University of Washington, 1959 NE Pacific St, Box 356420, Seattle, WA 98195-6420. fore 1976 as well as to search for articles not included in the original search.

\section{Some Common Medical Myths Case 1}

An 84-year-old woman is seen in clinic for weakness and fatigue. When she is examined, her mental status is normal, and there is evidence of bilateral lower extremity neuropathy. Her hematocrit is 23 percent, hemoglobin $7.3 \mathrm{~g} / \mathrm{dL}$, and mean corpuscular volume $117 / \mathrm{\mu m}^{3}$. Her serum cobalamin level is $80 \mathrm{pg} / \mathrm{mL}$ (normal > $200 \mathrm{pg} / \mathrm{mL}$ ), and her urinary methylmalonic acid level is high. A Schilling test is abnormal and corrects with addition of intrinsic factor, indicating pernicious anemia. She is given loading loses of hydroxocobalamin intramuscularly and told she will need a monthly injection of hydroxocobalamin to manage her disease.

Myth 1: Replacement for vitamin $B_{12}$ deficiency caused by pernicious anemia must not be done orally.

The classic teaching in medical school is that vitamin $B_{12}$ deficiency in patients with pernicious anemia is due to poor $B_{12}$ absorption because of lack of intrinsic factor and that replacement must be given intramuscularly. This belief was expressed in the following statement by the United States Pharmacopeia Anti-Anemia Preparations Advisory Board: "In the management of a disease for which parenteral therapy with Vitamin $B_{12}$ is a completely adequate and wholly reliable form of therapy, it is unwise to employ a type of treatment which is, at best, unpredictably effective."

Studies in the 1950 s showed that vitamin $B_{12}$ could be absorbed orally by patients with pernicious anemia and that two mechanisms of absorption of $B_{12}$ exist, one that involves intrinsic factor and one that does not. ${ }^{4}$ Several studies showed that oral replacement with vitamin $B_{12}$ could lead to resolution of the anemia. ${ }^{5-8}$ With oral vitamin 
$B_{12}$ doses of less than $300 \mu \mathrm{g} / \mathrm{d}$, daily serum levels were usually not in the normal range. ${ }^{5,7}$ Normal serum levels were readily achieved, however, when patients received 300 to $1000 \mu \mathrm{g}$ of vitamin $B_{12}$ daily. ${ }^{5,6}$ In one study all 64 patients receiving oral daily dosages of 500 or $1000 \mu \mathrm{g}$ of vitamin $B_{12}$ for pernicious anemia had normal serum $B_{12}$ levels, normalized hemoglobin levels, and no neurologic complications at follow-up through 5 years. ${ }^{6}$ Daily oral replacement of vitamin $B_{12}$ with 1000 $\mu \mathrm{g}$ keeps body stores of $\mathrm{B}_{12}$ as adequately filled as monthly intramuscular delivery. ${ }^{9}$

The costs of oral and parenteral vitamin $B_{12}$ replacement are comparable. The cost of 100 tablets of $1000 \mu \mathrm{g}$ of vitamin $B_{12}$ is less than $\$ 10$. Thirty injection doses of $B_{12}$ are also less than $\$ 10$, but charges for administration either by clinic personnel or a visiting nurse dramatically increase the monthly cost. Even if patients were able to give themselves the vitamin $B_{12}$ injection, there would be additional costs for the monthly syringes, needles, and alcohol wipes.

Why is oral vitamin $B_{12}$ not widely used for replacement? Most physicians do not believe that vitamin $B_{12}$ can be replaced orally. In a survey of internists, 94 percent were not aware of an available, effective oral therapy for $\mathrm{B}_{12}$ replacement. ${ }^{10}$ In the same survey, 88 percent of the internists stated that an oral replacement form of vitamin $B_{12}$ would be useful in their practice.

This myth combines several features found in medical myths. It makes some sense from a pathophysiologic standpoint-vitamin $B_{12}$ requires intrinsic factor; if the patient does not have intrinsic factor, how would the patient absorb $B_{12}$ ? The studies that refuted the myth were published during a time (1960s) when oral vitamin $B_{12}$ was not available in the United States, so oral replacement did not become standard practice. Finally, the earliest results of studies of oral vitamin $B_{12}$ replacement using low doses of $B_{12}$ were failures.

\section{Case 2}

A 26-year-old man is evaluated for right eye pain. $\mathrm{He}$ was poked in the eye while playing basketball. He describes considerable right eye discomfort but no visual changes. On examination with fluorescein, he has evidence of a corneal abrasion. He is instructed to wear an eye patch over the right eye for the next 48 hours.
Myth 2: Patching the eye improves comfort and bealin in patients with corneal abrasions.

The traditional treatment for corneal abrasion has been to apply a firm eye patch for severah days. ${ }^{11}$ This standard approach is not based on an $\bar{y}$ evidence of benefit of healing or decreased pain. study in 1960 evaluated differences in healing of corneal abrasions comparing patients wearing a eye pad with patients not wearing an eye pad. No differences were seen in healing, and the au $\frac{\bar{\sigma}}{\overline{0}}$ thor concluded that simple corneal abrasion $\overline{\mathrm{c}}$ should be treated without an eye pad. ${ }^{12}$ Severad more recent studies have supported the recommendation to avoid patching the eye of patient $\dot{s}^{\circ}$ with simple corneal abrasions. ${ }^{13-15}$ The largest of these studies involved 201 patients with cornea abrasions. ${ }^{14}$ The patients who did not receive at eye patch had less pain and quicker healing of the corneal abrasions.

No human studies were done to support the्ह initial use of eye patches for the treatment of corneal abrasions. The first study questioning this practice, published in 1960, showed no benefit of eye patching. Despite evidence to the contrary eye patching continued to be the standard of care for treatment of corneal abrasions and still is common treatment offered for patients witl corneal abrasion. ${ }^{16}$

\section{Case 3}

A 48-year-old man with type 1 diabetes comes in for primary care. He has a history of gout, hyper tension, and coronary artery disease, and he suffered a myocardial infarction 9 months ago. His hypertension was treated with lisinopril, but the medication was stopped 2 months later becaus he developed angioedema. His blood pressure ise $160 / 95 \mathrm{mmHg}$, and his pulse is 80 beats per minute; he has nonproliferative retinopathy in both eyes and bilateral neuropathy in both lowes extremities. Diltiazem is prescribed for his hyper tension.

Myth 3: Patients with diabetes are at increased ris for bypoglycemic unawareness if they are taking $a_{0}$ $\beta$-blocker.

This patient with diabetes meets treatment guide $-\frac{0}{0}$ lines for pharmacologic therapy for his hyperten $\frac{\vec{D}}{\vec{Q}}$ sion. A $\beta$-blocker would offer both antihyperten $\stackrel{\infty}{\circ}$ sive treatment and a cardioprotective benefit after a myocardial infarction. Concern about the sidę 
effects of $\beta$-blockers appears to limit their use despite clear evidence of benefit. In the Cardiac Arrhythmia Suppression Trial (CAST) study ${ }^{17} 50$ percent of the patients received a calcium channel blocker after a myocardial infarction and approximately 30 percent received a $\beta$-blocker. The cardiovascular benefit of $\boldsymbol{\beta}$-blockers in patients with diabetes who have had a myocardial infarction is striking. The mortality benefit in patients with diabetes who are given a $\beta$-blocker after a myocardial infarction is 48 percent, with a 78 percent decrease in reinfarction. ${ }^{18}$

For patients with insulin-treated diabetes there is concern about $\beta$-blockers reducing or eliminating the warning symptoms of hypoglycemia. This concern was addressed by Barnett et $\mathrm{al}^{19}$ in a prospective study of 150 patients who had insulintreated diabetes. Fifty diabetic patients on insulin taking $\beta$-blockers were compared with 100 diabetic patients on insulin not taking $\beta$-blockers. The patients kept a diary, recording all episodes of hypoglycemia and all warning symptoms. The incidence of loss of consciousness from hypoglycemia was the same in both groups and was not related to the dose of $\beta$-blocker used. All symptoms of hypoglycemia were similar in both groups with the exception of diaphoresis, which was more common in the $\beta$-blocker group.

In another study patients with diabetes on $\beta$-blockers were given insulin infusions to reduce blood glucose levels, and symptoms were recorded. The patients on $\beta$-blockers did not have hypoglycemic unawareness. They did have adrenergic symptoms at lower blood glucose levels than did the diabetic control group not on $\beta$-blockers, but their overall symptom scores were greater because of an increased perception of diaphoresis in the patients taking $\beta$-blockers. ${ }^{20}$ In a recent retrospective cohort study, more than 13,000 patients with diabetes treated with either oral hypoglycemics or insulin were studied to find out whether antihypertensive agents predisposed them to serious hypoglycemic events. No class of antihypertensive medication (including $\beta$-blockers) was found to predispose these patients to serious hypoglycemic events. ${ }^{21}$

\section{Case 4}

A 67-year-old man is admitted with severe chest pain, and an acute inferior myocardial infarction is diagnosed. He undergoes coronary artery catheterization and has atherosclerotic disease in his left anterior descending and right coronary arteries. $\mathrm{He}$ is given atenolol, simvastatin, aspirin, and nitroglycerin (as needed). Three months after the infarct, he returns to the clinic with symptoms of insomnia, difficulty concentrating, feelings of worthlessness, and fatigue. He has no history of depression. His atenolol is tapered off, and sertraline is prescribed.

Myth 4: $\beta$-Blockers are an important cause of depression. Early reports of possible $\beta$-blocker-induced depression surfaced soon after the $\beta$-blocker propranolol became available in the 1960s. A frequently cited reference is a letter published in the British Medical Fournal in which Waal ${ }^{22}$ reported that 20 of 89 patients on propranolol volunteered or exhibited depressive symptoms. Forty percent of these cases were classified as grade 1 depressionsymptoms of irritability, insomnia, nightmares, and fatigue. No control group of patients was evaluated to ascertain the prevalence of these symptoms in patients treated with other antihypertensive medications or in nonhypertensive patients. Pollack et $\mathrm{al}^{23}$ described a series of 3 patients who developed symptoms of depression after starting propranolol and concluded that depression coming after the administration of propranolol was a real phenomenon.

A number of studies have concluded that there appears to be no increased prevalence of depression in patients on $\beta$-blockers. ${ }^{24-29}$ Schleifer et $\mathrm{al}^{24}$ evaluated for evidence of depression 190 patients who had sustained a myocardial infarction. The patients were interviewed 8 to 10 days after the infarct and again at 3 months. No antianginal or antihypertensive medication including $\beta$-blockers was associated with an increase in depression. Using a psychiatric interview and psychologic assessments, Carney et al ${ }^{25}$ evaluated 75 patients undergoing elective cardiac catheterization. One half of the patients in the study were receiving $\beta$-blockers. Thirty-three percent of the patients who were not receiving $\beta$-blockers met Diagnostic and Statistical Manual or Mental Disorders, ed 3 (DSM-III) criteria for depression, and 21 percent of the patients taking $\beta$-blockers met criteria for depression.

In a study of depression in new users of antihypertensive medications in the Harvard Community Health Plan medication registry, the rates of depression were no higher in those taking $\beta$ - 
blockers than in those taking other antihypertensive medications. ${ }^{27}$ Using the records of the Saskatchewan prescription drug plan, Thiessen et $\mathrm{al}^{28}$ studied the rates of antidepressant prescriptions written after $\beta$-blockers were prescribed and found that 6.4 percent of $\beta$-blocker users received a prescription for an antidepressant within 30 days compared with 2.8 percent of the reference group. A similar study design by Hallas ${ }^{30}$ showed no increase in antidepressant prescribing after patients received a $\beta$-blocker.

A great deal of concern about the possibility of $\beta$-blockers causing depression was generated by early case reports and subsequent case series. None of these reports evaluated the frequency of depression in a control group. Confounding the issue is the side effect of fatigue, which is frequently reported in patients on $\beta$-blockers. ${ }^{31} \mathrm{~Pa}$ tients might have depression incorrectly diagnosed if fatigue is the only depressive symptom. Depression occurring after major medical illness such as an myocardial infarction is common. As several studies have shown, ${ }^{24,25}$ depression is common in patients with coronary artery disease regardless of what specific medications they are taking. Unfortunately, no large controlled prospective trials have addressed the issue of depression in patients taking $\beta$-blockers. The beneficial effects of $\beta$-blockers should not be overlooked in patients who have a history of depression, as the small possibility of a depressive effect caused by the $\beta$-blocker might well be outweighed by its beneficial effect.

\section{Case 5}

A 33-year-old man comes to the emergency department with acute abdominal pain. He had the sudden onset of pain in the middle of his abdomen about 2 hours earlier. The pain is worse with movement, particularly during the car ride to the hospital. He recently injured his leg snowboarding and has been taking a large amount of aspirin to relieve the pain. When examined, the patient has a rigid abdomen with tenderness on palpation. He asks for pain medication but is told he needs to be evaluated by the surgeon before medication can be considered.

Myth 5: Giving narcotics to a patient with a possible acute abdomen might mask the signs and make it difficult to make a diagnosis.
Standard teaching in medical school has been not to give narcotics to patients with possible acu留 abdomen syndromes, as the narcotic could mas important signs and delay or prevent an accura diagnosis. Cope's Early Diagnosis of the Acute A domen, ${ }^{32}$ a book read by most medical student has endorsed this position. This quote was in the 15th edition: "If morphine be given, it is possibet for a patient to die happy in the belief that he is the road to recovery, and in some cases the mede. ical attendant may for a time be induced to shate the elusive hope." An even stronger position wầ taken in the next edition of Cope's text ${ }^{33}$ : "The patient cried out for relief, the relatives are insisterat that something should be done, and the humaries disciple of Aesculapius may think it is his first du to diminish or banish the too obvious agony $\mathrm{b} \overrightarrow{\vec{F}}$ administering a narcotic. Such a policy is a miştake. Though it may appear cruel, it is really king to withhold morphine until a reasonable diagnosis has been made."

No controlled trials ever questioned this long $\vec{z}$ held belief until Attard et al ${ }^{34}$ published the resuls of a study done in 1992 . In this study 100 patients were evaluated by an admitting officer and give $\$$ either a narcotic or saline intramuscularly. Suto geons who subsequently cared for the patients fe equally confident in diagnosis and management i both groups. The decision to operate or observ was incorrect in 2 patients in the narcotic grou and 9 in the saline group. Another recent study used intravenous morphine or placebo in $71 \mathrm{p}$ 镸 tients for treatment of acute abdominal pain There were no differences in accuracy of diagno sis between groups. Three diagnostic or manage ment errors were made in each group. This myt $\mathbb{B}$ has been spread both through the use of a well-res spected text and by surgical dogma. The hypothe sis made some sense, so it was not tested for man years. Now, with two placebo-controlled trial\$ showing no harm with pain control, practice might start to change, though it will take a longe time for the effect of several generations of belied to change.

\section{Case 6}

A 58-year-old woman with type 2 diabetes is ad mitted to the hospital for treatment of a diabetio foot ulcer. She has noticed rising blood glucos $\frac{\mathbb{Q}}{\mathrm{Q}}$ levels during the past week as her ulcer worsened Her other medical problems include coronarp 
artery disease with a history of a myocardial infarction 2 years ago, and a history of hypertension. Her medications include isosorbide dinitrate 20 $\mathrm{mg}$ orally three times a day, enalapril $10 \mathrm{mg}$ orally every morning, enteric-coated aspirin $325 \mathrm{mg}$ daily, and glyburide $10 \mathrm{mg}$ orally twice a day. Laboratory values at admission were as follows: sodium $130 \mathrm{mEq} / \mathrm{L}$, potassium $3.8 \mathrm{mEq} / \mathrm{L}$, chloride $98 \mathrm{mEq} / \mathrm{L}$, bicarbonate $24 \mathrm{mEq} / \mathrm{L}$, and glucose $440 \mathrm{mg} / \mathrm{dL}$. She is given intravenous ampicillin-sulbactam for her foot ulcer and begins a sliding scale insulin regimen for management of her diabetes.

\section{Myth 6: Sliding scale insulin therapy is effective and appropriate therapy for managing diabetes in bospital- ized patients.}

Most training in the management of diabetes mellitus in the United States takes place during medical school and residency in the inpatient setting. Sliding scale insulin injections are a commonly used management strategy for hospitalized inpatients. ${ }^{36,37}$ In a study of medical inpatients, physicians prescribed a sliding scale regimen for 61 percent of 218 patients with a history of diabetes who were admitted to the hospital for reasons other than metabolic control. ${ }^{38}$ It is not clear how this practice began. There are no studies showing benefit of a sliding scale approach to diabetes management. It became firmly entrenched as a popular method of so-called "cookbook" medicine, usually learned during residency training. ${ }^{36}$

Initial sliding scale insulin regimens were based on urine glucose levels. Current sliding scale insulin regimens are based on regularly obtained fingerstick glucose values, usually obtained at 4- to 6hour intervals. Problems with this approach include giving insulin retrospectively for high blood glucose levels and not giving any insulin when the patient achieves euglycemia regardless of caloric intake. Insulin is not given in anticipation of rising blood glucose levels with meals. Patients frequently receive blood glucose monitoring at bedtime or even during the night when there is no food intake. Treating elevated evening blood glucose levels with regular insulin increases the risk of hypoglycemic episodes while the patient is asleep and less likely to be able to call for assistance.

Several studies have evaluated the efficacy of sliding scale insulin therapy. Gearheart et al ${ }^{39}$ evaluated outcomes of patients admitted for treat- ment of diabetic ketoacidosis. Insulin therapy was categorized into either sliding scale, proactive (prospective regimen of insulin in anticipation of glucose levels), or combination (routine insulin ordered with an additional sliding scale). Patients given sliding scale insulin had higher median glucose values than those on the other two regimens. The patients who received the proactive regimen were hospitalized for fewer days (4.4 days) than those in the combination group (6.3 days) and sliding scale group (6.3 days). MacMillan ${ }^{40}$ also found similar problems with sliding scale insulin. In a retrospective study of children admitted with diabetic ketoacidosis, the group who received sliding scale insulin had a longer duration of ketosis and worse glucose control than those who received long-acting insulin.

In a recent study Queale et $\mathrm{al}^{41}$ reviewed the diabetes management of 171 hospitalized patients, of whom 130 were given sliding scale insulin regimens. When used alone (without longacting insulin), the sliding scale insulin regimens were associated with a threefold higher risk of hyperglycemic episodes compared with no pharmacologic regimen. This study also touches on another problem with sliding scale insulin regimens-they are rarely modified. Patients at higher risk in this study for hypoglycemia were men with low body weight and those patients with low serum albumin levels. The sliding scale regimen written on admission was rarely ever modified during the hospitalization. ${ }^{41}$

Alternatives to sliding scale insulin for management of the hospitalized patient with diabetes include intravenous insulin drips in the patient who is not able to eat or long-acting daily insulin with premeal adjustments in regular insulin dosing based on an insulin algorithm. ${ }^{42}$ Algorithms differ from sliding scales in that they are connected to meal times and take into account calorie load and activity level. ${ }^{42,43} \mathrm{~A}$ key factor in safely giving insulin in the hospital setting is checking blood glucose levels around meal time and making any adjustment to short-acting insulin doses based on both premeal glucose level and anticipated caloric intake.

Why did sliding scale insulin use become such a widespread practice? It reduces diabetes management into a simple, easy-to-remember formula and probably endured for this reason despite no evidence in the literature to support it. Sliding 
scale insulin allows preordered insulin dosages to be given automatically based on serum glucose monitoring without interrupting the physician for intermittent insulin orders. The few studies that have been published suggest it is an inferior management choice compared with longer acting insulin or intravenous insulin infusions.

\section{Summary}

Medical myths occur for many different reasons. A common thread is that they all make some pathophysiologic sense. A good example is the concern about using oral cobalamin when treating pernicious anemia. The difficulty in absorbing vit$\operatorname{amin} B_{12}$ when intrinsic factor is not available does not make oral replacement impossible; the dose just needs to be higher. Pathophysiologic concerns have also been a key reason why physicians have avoided using $\beta$-blockers in patients with diabetes. They fear that $\beta$-blockers will block adrenergic symptoms, and patients will not know when they are hypoglycemic. In studies addressing this issue, there appears to be no real problem with increased severe episodes of hypoglycemia in patients on $\beta$-blockers or increased hypoglycemic unawareness. Several studies commented on the unanticipated symptom of increased sweating associated with hypoglycemia in diabetic patients who are taking $\beta$-blockers.

Another important concept behind some medical myths is the overreliance on case reports or authoritative text. The concern about depression associated with $\beta$-blocker use grew out of one widely referenced case report. ${ }^{5}$ Subsequent studies have not shown convincing evidence for a strong association with $\beta$-blocker use and depression. The strong position taken against narcotic use in Cope's Early Diagnosis of the Acute Abdomen is probably the reason for the perpetuation of the myth of avoiding narcotics for pain relief in patients with undiagnosed acute abdominal conditions. The only two studies addressing this issue showed no problems with diagnosis caused by providing narcotic pain relief. 29,30

Newer therapies usually undergo closer scrutiny before being accepted, often including placebo-controlled trials to show the efficacy of a medication. Such might not be the case with newer technologies. It is harder to evaluate the benefit of a new technology in the face of noncomparable previous technologies. Catheteriza- tion of the right side of the heart (Swan-Gan catheter) was a technology that became wideI used before any outcome studies became availableू Multiple reports in the last decade have shown in? creased mortality and increased utilization of re sources in patients who received catheterization of the right side of the heart. ${ }^{44,45}$ Most new drug therapies require randomized data to show effects before widespread use and acceptance occui Older therapies that have been widely accepte for a long time might not have had controlled tria data behind recommendations for their use, and once practice patterns become widespread, it is hard to change.

It is always good to ask the question, "Will this help my patient live better or longer?" when preo scribing a therapy. These myths underscore the importance and utility of outcome-based researct $\vec{n}$ to help guide physicians in their practices.

\section{References}

1. Davis DA, Thomson MA, Oxman AD, Haynes RE Changing physician performance. A systematic re view of the effect of continuing medical education. strategies. JAMA 1995;274:700-5.

2. Evans CE, Haynes RB, Birkett NJ, Gilbert JR, Taylor DW, Sackett DL, et al. Does a mailed continuing medical education program improve physician pers formance? Results of a randomized trial in antihy pertensive care. JAMA 1986;255:501-4.

3. Bethell FH, Castle WB, Conley CL, London IM Present status of treatment of pernicious anemia ninth announcement of USP anti-anemia preparas tions advisory board. JAMA 1959;171:2092-4.

4. Doscherholmen A, Hagen PS. A dual mechanism of vitamin B12 plasma absorption. J Clin Invest 1957 36:1551-7.

5. Brody EA, Estren S, Wasserman LR. Treatment o产 pernicious anemia by oral administration of vitamib B12 without added intrinsic factor. $\mathrm{N}$ Engl J Me 1959;260:361-7.

6. Berlin H, Berlin R, Brante G. Oral treatment of perni⿵ cious anemia with high doses of vitamin B12 withous intrinsic factor. Acta Med Scand 1968;184:247-58.

7. McIntyre PA, Hahn R, Masters JM, Krevans JRÑ Treatment of pernicious anemia with orally adminis tered cyanocobalamin (vitamin B12). Arch Inter这 Med 1960;106:280-92.

8. Waife SO, Jansen CJ, Crabtree RE, Grinnan EL Fouts PJ. Oral vitamin B12 without intrinsic factor in the treatment of pernicious anemia. Ann Intern Medicine 1963;58:810-7.

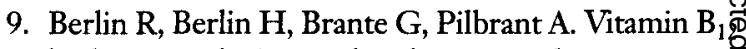
body stores during oral and parenteral treatment of pernicious anaemia. Acta Med Scand 1978;204(1 2):81-4. 
10. Lederle FA. Oral cobalamin for pernicious anemia. Medicine's best kept secret? JAMA 1991;265:94-5.

11. Pousada L. Emergency medicine. Baltimore: Williams \& Wilkins, 1989

12. Jackson $H$. Effect of eye pads in healing of simple corneal abrasions. Br Med J 1960;2:713.

13. Hulbert MF. Efficacy of eyepad in corneal healing after corneal foreign body removal. Lancet 1991; 337: 643.

14. Kaiser PK. A comparison of pressure patching versus no patching for corneal abrasions due to trauma of foreign body removal. Ophthalmology 1995;102: 1936-42.

15. Kirkpatrick JN, Hoh HB, Cook SD. No eye pad for corneal abrasions. Eye 1993;7:468-71.

16. Sprague J. Eye injuries. In: Harwood-Nuss A, editor. The critical practice of emergency medicine. Philadelphia: JB Lippincott, 1996.

17. Preliminary report: effect of encainide and flecainide on mortality in a randomized trial of arrhythmia suppression after myocardial infarction. The Cardiac Arrhythmia Suppression Trial (CAST) Investigators. N Engl J Med 1989;321:406-12.

18. Kendall MJ, Lynch KP, Hjalmarson A, Kjekshus J. Beta-blockers and sudden cardiac death. Ann Intern Med 1995;123:358-67.

19. Barnett AH, Leslie D, Watkins PJ. Can insulintreated diabetics be given beta-adrenergic blocking drugs? Br Med J 1980;280:976-8.

20. Hirsch IB, Boyle PJ, Craft S, Cryer PE. Higher glycemic thresholds for symptoms during beta-adrenergic blockade in IDDM. Diabetes 1991;40:1177-86.

21. Shorr RI, Ray WA, Daugherty JR, Griffin MR. Antihypertensives and the risk of serious hypoglycemia in older persons using insulin or sulfonylureas. JAMA 1997;278:40-3.

22. Waal HJ. Propranolol - induced depression. Br Med J 1967;2:50.

23. Pollack MH, Rosenbaum JF, Cassem NH. Propranolol and depression revisited: three cases and a review. J Nerv Ment Dis 1985;173:118-9.

24. Schleifer SJ, Slater WR, Macari-Hinson MM, Coyle DA, Kahn M, Zucker HD, et al. Digitalis and betablocking agents: effects on depression following myocardial infarction. Am Heart J 1991;121:1397-402.

25. Carney R, Rich MW, teVelde A, Saini J, Clark K, Freedland KE. Prevalence of major depressive disorder in patients receiving beta-blocker therapy versus other medications. Am J Med 1987;83:223-6.

26. Sorgi P, Ratey J, Knoedler D, Arnold W, Cole L. Depression during treatment with beta-blockers: results from a double-blind placebo-controlled study. J Neuropsychiatry Clin Neurosci 1992;4:187-9.

27. Gerstman BB, Jolson HM, Baver M, Cho P, Livingson JM, Platt $R$. The incidence of depression in new users of beta-blockers and selected antihypertensives. J Clin Epidemiol 1996;49:809-15.

28. Thiessen BQ, Wallace SM, Blackburn JL, Wilson TW, Bergman U. Increased prescribing of antide- pressants subsequent to beta-blocker therapy. Arch Intern Med 1990;150:2286-90.

29. Palac DM, Cornish RD, McDonald WJ, Middaugh DA, Howieson D, Bagby SP. Cognitive function in hypertensives treated with atenolol or propranolol. J Gen Intern Med 1990;5:310-8.

30. Hallas J. Evidence of depression provoked by cardiovascular medication: a prescription sequence symmetry analysis. Epidemiology 1996;7:478-84.

31. Adverse reactions to bendrofluazide and propranolol for the treatment of mild hypertension. Report of Medical Research Council Working Party on Mild to Moderate Hypertension. Lancet 1981;2:539-43.

32. Silen W, editor. Cope's early diagnosis of the acute abdomen, 15th ed. New York: Oxford University Press, 1979.

33. Silen $W$, editor. Cope's early diagnosis of the acute abdomen, 16th ed. New York: Oxford University Press, 1983.

34. Attard AR, Corlett MJ, Kidner NJ, Leslie AP, Fraser IA. Safety of early pain relief for acute abdominal pain. BMJ 1992;305:554-6.

35. Pace $S$, Burke TF. Intravenous morphine for early pain relief in patients with acute abdominal pain. Acad Emerg Med 1996;3:1086-92.

36. Katz CM. How efficient is sliding-scale insulin therapy? Problems with a 'cookbook' approach in hospitalized patients. Postgrad Med 1991;89:46-8, 51-4, 57.

37. MacMillan DR. Insulin adjustment by the sliding scale method - a straw man who won't stay down? J Ky Med Assoc 1991;89:211-2.

38. Queale WS, Sadler AJ, Bancati FL. The use of sliding scales in medical inpatients with diabetes mellitus. $\mathbf{J}$ Gen Intern Med 1995;10(Suppl):47.

39. Gearhart JG, Duncan JL 3rd, Replogle WH, Forbes RC, Walley EJ. Efficacy of sliding-scale insulin therapy: a comparison with prospective regimens. Fam Pract Res J 1994;14:313-22.

40. MacMillan DR. The fallacy of insulin adjustment by the sliding scale.J Ky Med Assoc 1970;68:577-9.

41. Queale WS, Seidler AJ, Brancati FL. Glycemic control and sliding scale insulin use in medical inpatients with diabetes mellitus. Arch Intern Med 1997;157: 545-52.

42. Hirsch IB, Paauw DS, Brunzell J. Inpatient management of adults with diabetes. Diabetes Care 1995;18: 870-8.

43. Hirsch IB, Farkas-Hirsch R, Skyler JS. Intensive insulin therapy for treatment of type I diabetes. Diabetes Care 1990;13:1265-83.

44. Connors AF Jr, Speroff'T, Dawson NV, Thomas C, Harrell FE Jr, Wagner K, et al. The effectiveness of right heart catheterization in the initial care of critically ill patients. SUPPORT Investigators. JAMA 1996;276:889-97.

45. Gore JM, Goldberg RJ, Spodick DH, Alpert JS, Dalen JE. A community-wide assessment of the use of pulmonary artery catheters in patients with acute myocardial infarction. Chest 1987;92:721-7. 